\title{
Review \\ Pathological Overeating: Emerging Evidence for a Compulsivity Construct
}

\author{
Catherine F Moore ${ }^{1,2}$, Valentina Sabino', George F Koob ${ }^{3}$ and Pietro Cottone ${ }^{*, 1}$ \\ 'Laboratory of Addictive Disorders, Departments of Pharmacology and Psychiatry, Boston University School of Medicine, Boston, MA, USA; \\ ${ }^{2}$ Graduate Program for Neuroscience, Boston University School of Medicine, Boston, MA, USA; ${ }^{3}$ National Institute on Alcohol Abuse and Alcoholism, \\ National Institutes of Health, Bethesda, MD, USA
}

\begin{abstract}
Compulsive eating behavior is a transdiagnostic construct that is characteristic of medical and psychiatric conditions such as forms of obesity and eating disorders. Although feeding research is moving toward a better understanding of the proposed addictive properties of food, the components and the mechanisms contributing to compulsive eating are not yet clearly defined or understood. Current understanding highlights three elements of compulsive behavior as it applies to pathological overeating: (I) habitual overeating; (2) overeating to relieve a negative emotional state; and (3) overeating despite aversive consequences. These elements emerge through mechanisms involving pathological habit formation through an aberrant learning process, the emergence of a negative emotional state, and dysfunctions in behavioral control. Dysfunctions in systems within neurocircuitries that comprise the basal ganglia, the extended amygdala, and the prefrontal cortex result in compulsive eating behaviors. Here, we present evidence to relate compulsive eating behavior and addiction and to characterize their underlying neurobiological mechanisms. A major need to improve understanding of compulsive eating through the integration of complex motivational, emotional, and cognitive constructs is warranted.

Neuropsychopharmacology (2017) 42, I375-1389; doi: 10.1038/npp.2016.269; published online 4 January 2017
\end{abstract}

\section{INTRODUCTION}

Compulsivity can be defined as repetitive behaviors in the face of adverse consequences, as well as repetitive behaviors that are inappropriate to a particular situation. Individuals suffering from compulsions often recognize that the behaviors are harmful, but they nonetheless feel emotionally compelled to perform them. Compulsivity shares some commonalities with impulsivity in that both constructs involve dysfunction in inhibitory control, likely mediated by frontal cortex projections to subcortical regions, but one defining feature of compulsivity is persistence where compulsivity is clearly repetitive and perseverative (Robbins et al, 2012). Compulsivity has historical roots in the symptoms related to obsessive-compulsive disorder, impulse control disorders, and substance use disorders and may involve engagement in compulsive behaviors to prevent or relieve distress, anxiety, or stress (American Psychiatric Association, 2000; Berlin and Hollander, 2014; el-Guebaly et al, 2012).

Compulsive behavior is a central feature of the characterization of not only substance use disorders and behavioral

\footnotetext{
*Correspondence: Dr P Cottone, Departments of Pharmacology and Psychiatry, Laboratory of Addictive Disorders, Boston University School of Medicine, 72 E Concord St, R-618, Boston, MA 02118, USA, Tel: 617 6385662, Fax: 617 6385668, E-mail: cottone@bu.edu Received 26 July 2016; revised 18 November 2016; accepted 22 November 2016; accepted article preview online 6 December 2016
}

addictions, but also of certain eating disorders, namely binge eating disorder (BED), of forms of obesity, as well as of the recently proposed construct of 'food addiction' (American Psychiatric Association, 2013; Davis, 2013; de Zwaan, 2001; Gearhardt et al, 2009; Volkow et al, 2013). In drug addiction, compulsive behavior manifests as a persistent drive to use drugs and an inability to control use; analogously, foodrelated pathologies present with an irresistible, uncontrollable urge to overeat despite efforts to control this behavior (Davis and Carter, 2009; Hone-Blanchet and Fecteau, 2014).

Much attention, and some controversy, has been aimed at defining and measuring compulsivity in drug addiction, bringing to light the complexity of the interpretation of compulsivity and its underlying etiology (Belin-Rauscent et al, 2015; Everitt, 2014; George et al, 2014; Hopf and Lesscher, 2014; Koob, 2013; Piazza and Deroche-Gamonet, 2013; Volkow and Fowler, 2000). However, so far very little work has been done in systematically defining compulsivity in the context of excessive eating behavior, leaving a gap in the current knowledge. The introduction of the Research Domain Criteria (RDoC) framework instituted by the National Institute of Mental Health has encouraged the scientific community to move toward a new way of classifying mental disorders, based on overarching, highlevel domains representing validated behavioral functions (The National Institute of Mental Health, 2013). This approach has recently been applied to addiction using a heuristic framework characterizing dynamic domains common to all addictions (Kwako et al, 2016); highlighting the 


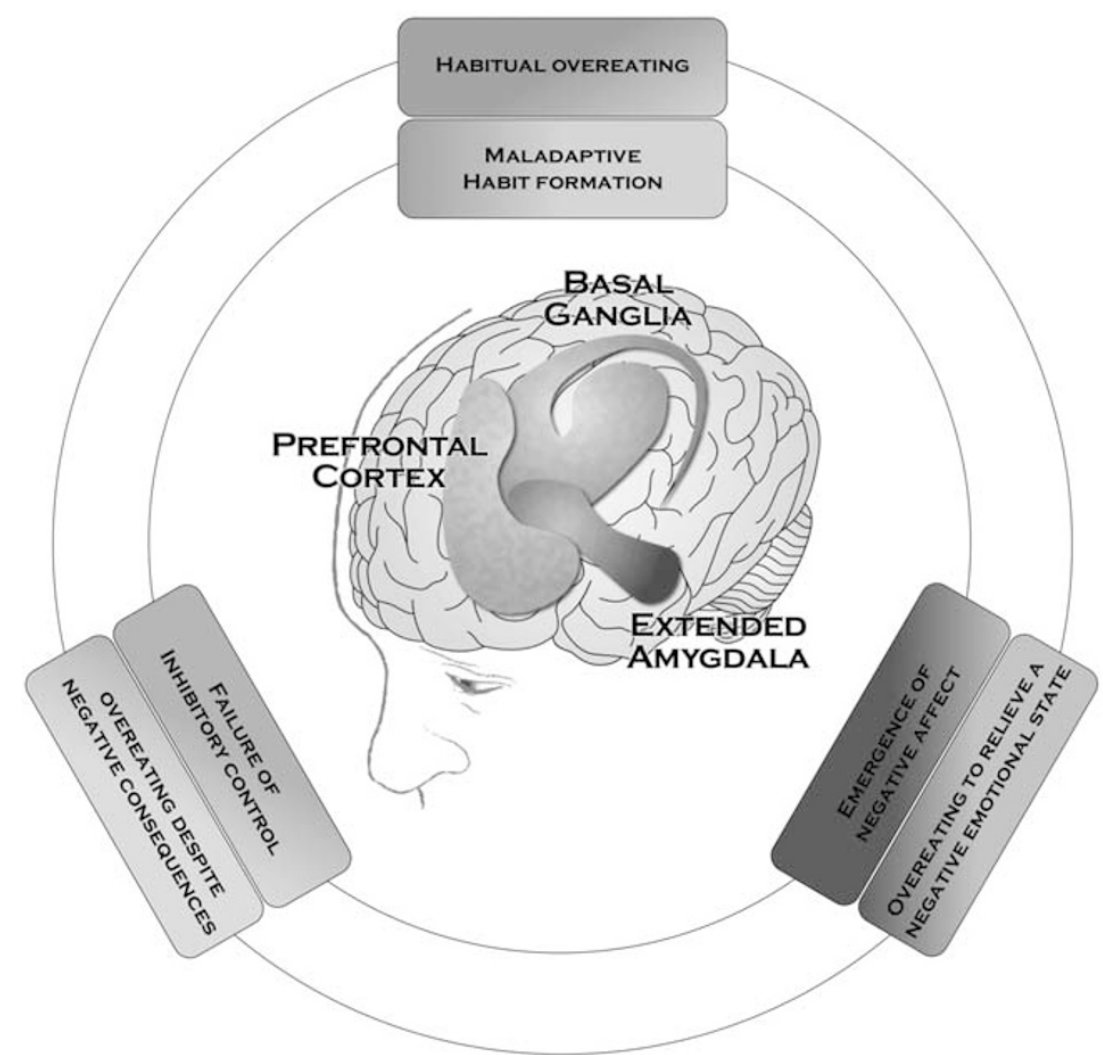

Figure I Neurobiology of the elements of compulsive overeating. The key systems that underlie the elements of compulsive eating are: (I) the basal ganglia, (2) the extended amygdala, and (3) the prefrontal cortex. The basal ganglia (shown in blue) consist of multiple subcortical nuclei, such as the nucleus accumbens (NAc), which is involved in the rewarding and reinforcing effects of food, and the dorsal striatum, which is involved in instrumental learning and habitual behavior. The basal ganglia contribute to habitual overeating that can arise from maladaptive habit formation processes. The extended amygdala (shown in red) is a basal forebrain composite structure encompassing the central nucleus of the amygdala (CeA), the bed nucleus of the stria terminalis (BNST), and a transition area in the medial and caudal portions of the NAc. The brain stress systems in the extended amygdala mediate overeating to relieve a negative emotional state that emerges from withdrawal processes. Prefronto-cortical regions (shown in green) include the medial prefrontal (mPFC, comprised of dorsolateral (dIPFC) and ventromedial (vmPFC) regions), anterior cingulate (ACC), and orbitofrontal (OFC) cortices; these areas control cognitive functions such as decision-making and response inhibition through interactions with subcortical structures such as the basal ganglia and the extended amygdala. Dysfunctions in the PFC are hypothesized to underlie overeating despite aversive consequences, reflecting failures in inhibitory control over behavior. Figure modified from Koob GF, Arends MA, Le Moal M. Drugs, Addiction, and the Brain. Academic Press, San Diego, 20l4. A full color version of this figure is available at the Neuropsychopharmacology journal online.

need for an evaluation of compulsive eating as a potential transdiagnostic construct across feeding-related disorders, as well as its underlying neural circuits.

This review aims to describe the compulsive eating behavior, which appertains to disorders of eating, such as $\mathrm{BED}$, some forms of obesity, and food addiction. In addition, it intends to clarify the most commonly accepted definitions of compulsivity postulated in the context of drug addiction as they apply to compulsive eating behavior. Drug addiction has been characterized as being composed of three stages: binge/ intoxication, withdrawal/negative effect, and preoccupationanticipation; these three stages, which provide a powerful impetus for the compulsive drug-seeking behavior, reflect incentive salience/pathological habits, reward deficits/stress surfeit, and executive function deficits, respectively (Koob and Volkow, 2016). We here claim that these same processes are responsible for the development of compulsive eating behavior of highly palatable food (ie, preferred foods rich in fat and/or sugars). Therefore, by analogy, three elements of compulsive eating behavior can be derived: (1) habitual overeating (Smith and Robbins, 2013; Tomasi and Volkow,
2013); (2) overeating to relieve a negative emotional state (Cottone et al, 2009a; Parylak et al, 2011); (3) overeating despite aversive consequences (Cottone et al, 2012; Johnson and Kenny, 2010; Figure 1). Similarly to what is observed in drug addiction, these elements of compulsive eating behavior are not always differentiable through observation, but can be attributed to distinct, albeit often intersecting, neurobiological mechanisms.

In this review, we will first describe the different disorders of eating characterized by compulsivity, and then define the three elements of compulsive eating. Within each element, we first summarize original and review articles important to the conceptualization of that element of compulsivity in addiction (drugs of abuse as well as food). We then describe studies, first in humans, and then in animals, detailing the behavioral manifestations of that element in feeding- and eating-related disorders. Finally, we discuss the neurobiological substrates hypothesized to underlie these processes in feeding-related disorders in humans and animals. The overall goal of this review is to systematically breakdown the proposed elements of 
Table I Diagnostic Criteria for Disorders Associated with Compulsive Overeating

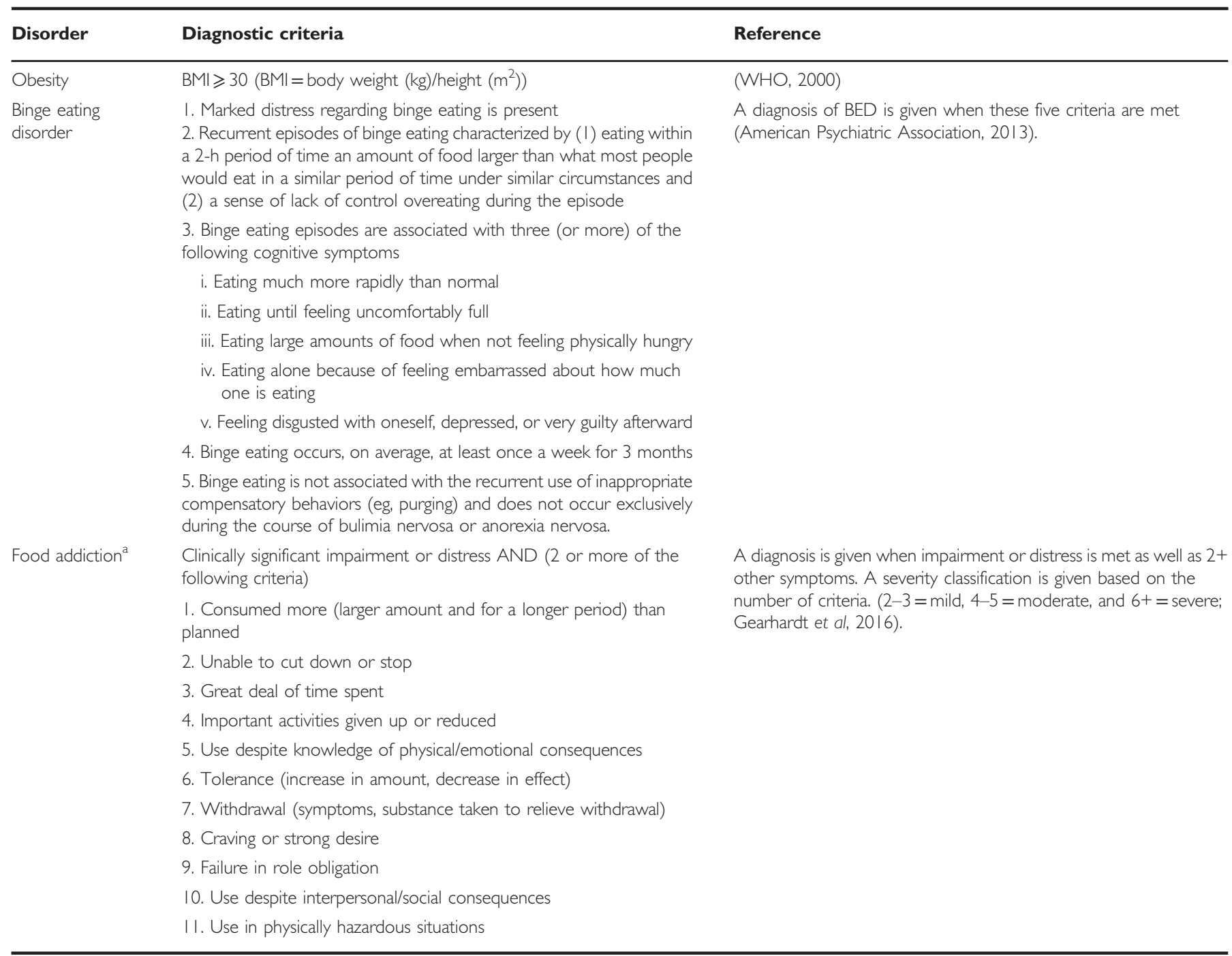

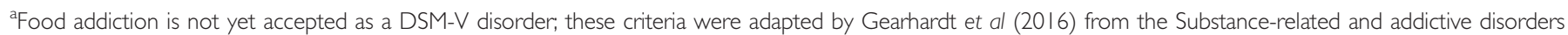
criteria within the DSM-V (APA, 20I3).

compulsive eating within the heterogeneous disorders of feeding behavior.

\section{COMPULSIVE EATING IN FORMS OF OBESITY AND EATING DISORDERS: PREVALENCE AND SIGNIFICANCE}

Compulsive eating behavior is characteristic of multiple disorders of eating, including BED, certain forms of obesity, and the newly proposed construct of 'food addiction' (diagnostic criteria for these disorders can be found in Table 1; APA, 2013; Gearhardt et al, 2016; Volkow et al, 2008a). Although diagnoses for BED and food addiction necessitate compulsive eating behaviors, this is not a diagnostic criterion for obesity, and overweight/obesity is neither necessary nor sufficient to characterize compulsive eating (Davis, 2013).

Obesity is becoming increasingly prevalent: with more than one-third $(35 \%)$ of the US population being obese, resulting in an estimated $\$ 147$ billion cost per year
(Finkelstein et al, 2009; Ogden et al, 2014). Although in the general population the prevalence of BED and food addiction are much lower (an estimated 2-5\% and 5-15\% for BED and food addiction, respectively; Davis et al, 2011; de Zwaan, 2001; Gearhardt et al, 2009; Kessler et al, 2013), these numbers increase 2-3 fold in obesity treatment-seeking populations (ie, Weight Watchers, low-energy diet, and bariatric surgery; de Zwaan, 2001; Pursey et al, 2014).

Individuals with BED and food addiction are much more likely to be overweight/obese (an estimated 40-70\%, respectively; Dingemans and van Furth, 2012; Kessler et al, 2013; Pursey et al, 2014). Obesity and BED are associated with significant impairments in health-related quality of life, increased direct health-care costs, and higher prevalence of comorbid psychiatric conditions (Agh et al, 2016; Dickerson et al, 2011; Fontaine and Barofsky, 2001; Halfon et al, 2013; Kessler et al, 2013; Wolf and Colditz, 1998). Individuals with food addiction have self-reported impairment and distress due to symptoms, and in adults with obesity and/or BED, an additional diagnosis of food addiction is associated with 
greater pathology and comorbid psychiatric disorders (Davis et al, 2011; Gearhardt et al, 2012). The high degree of comorbidity among these feeding and eating disorders may reflect shared etiologies and/or underlying mechanisms, manifesting in some cases through compulsive eating behaviors.

\section{ELEMENTS OF COMPULSIVE EATING BEHAVIOR}

Compulsive eating behavior is posited to be a combination of one or more of the following elements: (1) habitual overeating, (2) overeating to relieve a negative emotional state, and (3) overeating despite aversive consequences. We propose that these elements emerge from dysfunctions of brain areas involved in reward learning, emotional processing, and inhibitory control. Although each of these processes involves multiple regions within interconnected circuits, for the purpose of this review, we will focus on three specific key areas implicated in the above discussed elements: the basal ganglia, the extended amygdala, and the prefrontal cortex (PFC; see Table 2 for a summary of features). Importantly, we acknowledge that these elements, although part of a unifying construct, are not mutually exclusive, nor would they all be necessary for the designation of a behavior as compulsive.

\section{HABITUAL OVEREATING}

\section{Psychobehavioral Feature: Maladaptive Habit Formation}

Maladaptive habit responding is hypothesized to begin with Pavlovian conditioning mechanisms (Belin and Everitt, 2008). Environmental food-associated stimuli, known as conditioned reinforcers, can robustly enhance the desire to eat even in absence of food per se or in absence of physiological needs (Everitt and Robbins, 2005; Robinson et al, 2015). With repeated pairings of a cue (conditioned stimulus) with food (unconditioned stimulus), the learned cue itself becomes salient (termed incentive salience), therefore triggering intense urges to obtain the associated reward, and also acts as a conditioned reinforcer able to maintain food seeking in the absence of food presentation (Giuliano et al, 2012; Velazquez-Sanchez et al, 2015; Giuliano and Cottone, 2015).

Habit formation is the end result of an adaptive learning process where voluntary actions become habitual through the reinforcement of these behaviors. It is hypothesized that compulsive behavior may reflect a maladaptive stimulusresponse habit that was once a flexible and voluntary goal-directed behavior (Everitt and Robbins, 2005; Halbout et al, 2016; Lucantonio et al, 2014; Ostlund and Balleine, 2008). Habits are formed through repeated reinforced action until the stimulus-response association lapses the goal of the behavior (eg, the palatable food or drug) as the motivation to perform the action (Everitt and Robbins, 2013). Outcome devaluation procedures are often used to assess whether a response has become habitual, through the measurement of perseverative responding after the value of the outcome (ie, drug/food reward) has been reduced. Habits can be considered compulsive when they persist despite devaluation, or a reduction in reinforcer efficacy (Everitt and Robbins, 2005). Analogously to what is observed in drug addiction, in compulsive eating disorders, the inability to adapt eating behavior based on the motivational value of the outcome may reflect a compulsive habit (Corbit, 2016; Everitt and Robbins, 2005; Voon et al, 2015).

Some evidence suggests that obese individuals are less sensitive to devaluation, indicative of increased habitual control over food intake. Specifically, a study found that higher BMI was inversely related to sensitivity of a foodseeking response to earlier consumption of that reward (Horstmann et al, 2015). This may suggest difficulty in adapting behavior subsequently contributing to food seeking or overconsumption; however, differences in respect to habituation to food may confound assessments using specific satiety as a measure of devaluation in obese participants (Epstein et al, 2009). Another study indicated a bias for individuals with BED to engage in habit learning devices compared with other types of learning, also seen in individuals with methamphetamine addiction and obsessivecompulsive disorder (Voon et al, 2015). This favoring of habit learning may underlie the compulsive habit responding that is characteristic of these disorders and represent a dysfunction in a neurocomputational mechanism of learning. In addition, individuals with BED, food addiction, and obesity all show heightened sensitivity and attentional biases to food cues at a behavioral level (Meule et al, 2012; Schmitz et al, 2014; Shank et al, 2015; for review see Garcia-Garcia et al, 2013; Hendrikse et al, 2015). These measures of increased sensitivity are related to food seeking, eating

Table 2 A Summary of the Features of Each Element of Compulsive Eating Behavior

\begin{tabular}{|c|c|c|c|c|}
\hline $\begin{array}{l}\text { Elements of } \\
\text { compulsive eating } \\
\text { behavior }\end{array}$ & $\begin{array}{l}\text { Neuropsychobiological } \\
\text { mechanisms }\end{array}$ & Characteristic behavior & $\begin{array}{l}\text { Most } \\
\text { implicated } \\
\text { brain area }\end{array}$ & Selected references \\
\hline Habitual overeating & Aberrant reward learning & $\begin{array}{l}\text { Inability to reduce eating or seeking } \\
\text { behavior following a decrease in food } \\
\text { value or contingency }\end{array}$ & Basal ganglia & $\begin{array}{l}\text { Horstmann et al, 2015; Furlong } \\
\text { et al, 2014; Corbit, } 2016\end{array}$ \\
\hline \multirow[t]{2}{*}{$\begin{array}{l}\text { Overeating to relieve a } \\
\text { negative emotional state }\end{array}$} & Affective habituation & $\begin{array}{l}\text { Eating to cope with decreased } \\
\text { sensitivity to reward }\end{array}$ & Basal ganglia & Johnson and Kenny, 2010 \\
\hline & Affective withdrawal & $\begin{array}{l}\text { Eating to cope with negative affect } \\
\text { (eg, anxiety and stress) }\end{array}$ & $\begin{array}{l}\text { Extended } \\
\text { amygdala }\end{array}$ & $\begin{array}{l}\text { Cottone et al, 2009a; Parylak } \\
\text { et al, 201 I }\end{array}$ \\
\hline $\begin{array}{l}\text { Overeating despite } \\
\text { negative consequences }\end{array}$ & Decreased inhibitory control & $\begin{array}{l}\text { Eating persists in conditions where it } \\
\text { would normally be suppressed }\end{array}$ & Prefrontal cortices & $\begin{array}{l}\text { Heyne et al, 2009; Balodis et al, } \\
\text { 2013b; Cottone et al, } 2012\end{array}$ \\
\hline
\end{tabular}

Neuropsychopharmacology 
(Lawrence et al, 2012), BMI (Shank et al, 2015), and severity of self-reported symptoms (Schmitz et al, 2014).

In animal models of addiction, habitual responding is measured through the persistence of responding following a devaluation of the reward outcome, such as the addition of bitter-tasting quinine, lithium-chloride-induced postingestive malaise, or specific satiety, where free access to the reward is given prior to the test. Similar to extended drug self-administration, prolonged intermittent access to palatable food was shown to accelerate the shift from voluntary to habitual food seeking (Furlong et al, 2014). Analogous to drugs of abuse, highly palatable food consumption can influence habitual responding, cognitive control, and learning to a greater degree than food with lower palatability (Smith et al, 2015; Velazquez-Sanchez et al, 2015).

Drug- and food-associated stimuli are able to elicit and maintain compulsive seeking behavior associated with drug or food craving (Everitt and Robbins, 2016). A classical experimental procedure used to discern seeking behavior from intake, is using a second-order schedule of reinforcement, where responding on a seeking lever is maintained not only by the self-administered drug/food, but also by contingent presentation of reinforcer-paired stimuli that serve as conditioned reinforcers of instrumental behavior (Everitt and Robbins, 2000; Velazquez-Sanchez et al, 2015). In this procedure, the first interval acquires particular relevance, as it is not influenced by the presence of the reinforcer (Everitt and Robbins, 2000). In drug addiction, seeking responses become resistant to devaluation through extinction or through the introduction of unpredictable shock over time in compulsive-like animals (Belin et al, 2008; Zapata et al, 2010). However, studies have not yet shown resistance to devaluation on food-seeking behavior under this schedule. In addition, related compulsive-like foodseeking behaviors seen in animals include continued responding on a food-paired lever during a period of signaled nonavailability (Mancino et al, 2015), and cueinduced reinstatement of responding following extinction (Nair et al, 2009).

\section{Neurobiological Substrate: The Basal Ganglia}

Structures of the basal ganglia, including the nucleus accumbens (NAc) and the dorsal striatum, are highly involved in the rewarding/reinforcing effects of food/drugs and in instrumental/habitual learning, respectively (Everitt and Robbins, 2005). One of the neurochemical similarities of food and drugs of abuse is the increase in extracellular dopamine in the NAc following exposure to associated cues (Day et al, 2007; Stuber et al, 2008). This potentiated dopaminergic neurotransmission to cues is hypothesized to result in increased incentive salience, and may similarly enhance habit learning (Everitt and Robbins, 2016), contributing to the emergence of compulsive-like behavior (dopamine system further discussed in the 'overeating to relieve a negative emotional state,' below; Peciña and Berridge, 2005; Robinson et al, 2015). In a study that used functional magnetic resonance imaging (fMRI), researchers found decreased activation in the caudate nucleus of the striatum (involved in goal-directed actions) and increased activity of the putamen (involved in habit responding) to palatable food taste in obese subjects as compared with healthy weight controls (Babbs et al, 2013). Thus, certain functional differences may exist in response to palatable food in habit-driven regions of the brain in obese individuals. There is also some evidence for associated structural differences in these habit learning systems. A study by Voon et al (2015) found obese subjects with BED displayed an increased tendency to engage in habit-based responding, associated decreases in ventral and dorsal striatal gray matter volume, and corresponding prefrontal projection areas compared with those without BED. This study suggests that impaired goal-directed learning in individuals with BED may be reflected in accelerated habit formation and structural abnormalities in areas responsible for action-outcome associations.

The habit learning processes implicated in the shift to addiction are accompanied by a ventral to dorsal striatal shift in the basal ganglia in control over behavior. Although the NAc is critical for the acquisition of drug or food selfadministration (goal-directed responding), the dorsal striatum is necessary for habitual behavior (Belin and Everitt, 2008; Corbit et al, 2012). Rats exposed to intermittent access to palatable food display a loss of goal-directed actions for food reward coupled with greater activation of the dorsolateral striatum (Furlong et al, 2014). Habitual behaviors are also influenced by indirect amygdalar projections to the dorsolateral striatum (Lingawi and Balleine, 2012) and prefronto-cortical control of flexible, goal-directed actions per its executive-inhibitory control functions. Thus preexisting vulnerabilities and/or modulation of frontal areas by palatable food are hypothesized to contribute to or exacerbate predominance of the shift to dorsal striatal control over habitual behavior (Everitt and Robbins, 2016). Therefore, both the amygdaloid anti-reward system and the prefrontocortical system influence the dorsal striatal-mediated facilitation of habit formation. This evidence is one demonstration that the different elements of compulsivity are not mutually exclusive and are based on overlapping neurobiological substrates.

\section{OVEREATING TO RELIEVE A NEGATIVE EMOTIONAL STATE}

\section{Psychobehavioral Feature: Emergence of a Negative Affect}

Performing a behavior such as taking a drug or ingesting palatable food for the purpose of alleviating a negative emotional state is another important element that defines compulsive behavior (Koob, 2009; Koob and Volkow, 2010; Parylak et al, 2011). This element of compulsivity is rooted in the conceptual framework underlying obsessive-compulsive disorder, which is characterized by anxiety and stress before committing a compulsive behavior, and relief from that stress by performing the behavior (Koob and Le Moal, 2008). Two distinct, but overlapping, processes are hypothesized to underlie this withdrawal-induced negative affect: decreased reward and increased stress. Decreased reward function is characterized by affective habituation and loss of motivation for ordinary rewards (Koob, 1996; Parylak et al, 2011). Negative affect also derives from recruitment of the brain stress systems, which are hypothesized to be repeatedly engaged during drug or palatable food withdrawal (Cottone 
et al, 2009a; Koob, 1999), leading to irritability and anxiety. Thus, as drug taking/eating becomes compulsive, the factors motivating behavior are hypothesized to shift: although at first the behavior is positively reinforced, later compulsivity would arise from negatively reinforcing mechanisms such as the relief of the negative emotional symptoms of withdrawal (Cottone et al, 2009a; Iemolo et al, 2012; Koob and Le Moal, 2001; Parylak et al, 2011; Teegarden and Bale, 2007). It should be noted that withdrawal in this context is separate from classically defined, purely 'physical' symptoms that occur upon removal of the substance (O'Brien, 2011). Instead, a motivational withdrawal syndrome, characterized by dysphoria, anxiety, and irritability when the reward sought is not available (Koob et al, 1997), is present in disorders of feeding and can drive compulsive eating behavior (Tao et al, 2010; Wray and Dickerson, 1981).

The concept of 'withdrawal' is very different in compulsive eating compared with drug addiction. Indeed, although drug users may quit drugs, abstinence from certain foods is achieved by dieting, reflected by a reduction in calories ingested and/or a shift from energy-dense, highly palatable 'forbidden' foods to energy-diffuse, less palatable 'safe' foods (Gonzalez and Vitousek, 2004; Stirling and Yeomans, 2004). In support of this, many reports have shown that obese people who started a dieting regimen report not only irritability and nervousness, but also intense anxiety (Keys et al, 1950; Silverstone and Lascelles, 1966; Stunkard, 1957). Furthermore, there is evidence that switching from a high-to low-fat diet can have adverse effects on mood (Wells et al, 1998). Indeed, dietary restraint is known to correlate with stress and depressive symptoms (Eldredge et al, 1990; Kagan and Squires, 1983; Rosen et al, 1990; Rosen et al, 1987), and these correlate with overeating in response to stress (Greeno and Wing, 1994; Heatherton et al, 1991), perhaps reflecting an attempt to self-soothe or self-medicate with 'comfort' foods (Macht, 2008; Tomiyama et al, 2011) as this eating can effectively dampen down the body's stress response (Pecoraro et al, 2004). Furthermore, the Kaplan and Kaplan theory proposes that obese people overeat when anxious and that eating reduces this anxiety (Kaplan and Kaplan, 1957). Similarly, Bruch's theory proposes that overeating occurs in response to 'emotional tension' and 'uncomfortable sensations and feelings' (Bruch, 1973). Taken together, these studies support the hypothesis that dieting may precipitate a negative emotional state, or an 'affective withdrawal,' and that compulsive eating may be maintained through a negatively reinforced mechanism (for further review, see Parylak et al, 2011).

Although withdrawal from palatable food is responsible for the emergence of negative affect and, in turn, hypothesized to drive compulsive eating through a negative reinforcement mechanism, abstaining from calorie-dense food also often implicates caloric restriction, which has wellknown effects on rebound binge eating and weight gain (Stice et al, 2008; Mann et al, 2007). A potential mechanism for this phenomenon is that food restriction itself causes neuroadaptations that promote certain compulsive behaviors, which includes compulsive-like eating as well as increased drug seeking in animals (Carr, 2016; Sedki et al, 2015; Shalev, 2012). However, it is important to distinguish that although food restriction and exposure to highly palatable food may produce similar behavioral outcomes, differential neuropsychopharmacological mechanisms likely mediate their effect (Cottone et al, 2009b; Cottone et al, 2012; Smith et al, 2015).

Notably, in addition to a perpetuation of compulsive eating, negative affective states that include symptoms associated with depression and anxiety may also confer vulnerability to (ie, predate) eating disorders and some forms of obesity, just as in addiction to drugs (Dallman et al, 2003; Rosenbaum and White, 2015). For example, individuals with BED have greater rates of psychiatric comorbidities involving negative emotional states compared with the general population and to weight matched controls (Galanti et al, 2007; Peterson et al, 2005). These negative emotional states are associated with greater binge eating behavior (Wilfley et al, 2000) and predict poorer treatment outcomes (Clark et al, 1996; Linde et al, 2004; McGuire et al, 1999). In drug addiction, it has been hypothesized that this vulnerability may reflect some degree of an already constituted state of allostasis; or a deviation from a 'normal' range of reward function (Koob and Le Moal, 2001).

In animal models, repeated, intermittent access to palatable food leads to spontaneous (Cottone et al, 2008, 2009b; Iemolo et al, 2012; Sharma et al, 2013) or pharmacologically precipitated (Avena et al, 2008a; Blasio et al, 2013; Colantuoni et al, 2002) emotional signs of withdrawal, such as anxiety- and depressive-like behavior, and enhanced stress-responsiveness. Following exposure to a high-fat diet, rats show elevated brain stimulation reward thresholds (decreased reward; Johnson and Kenny, 2010). A similar decreased reward system functioning is also observed in obesity-prone rats, prior to the development of obesity (Valenza et al, 2015), indicating that the decreased reward system functioning is both a vulnerability factor (Valenza et $a l, 2015)$ as well as a consequence of the overconsumption of palatable food (Johnson and Kenny, 2010). Renewing access to palatable food following abstinence induces overconsumption of palatable food (Avena et al, 2008a; Colantuoni et al, 2002; Cottone et al, 2009b; Rossetti et al, 2014), and this renewed access is able to relieve withdrawalinduced depressive and anxiety-like behaviors (Iemolo et al, 2012). Thus, evidence from animal models strongly suggests that pathological eating can contribute to the emergence of a negative emotional state, and that relief of anxiety or stress can drive compulsive eating behavior.

\section{Neurobiological Substrates: The Basal Ganglia and Extended Amygdala}

The neurobiological substrates that underlie this element of compulsivity are dual: within-system neuroadaptations, which refer to the downregulation of reward neurotransmission (Koob and Bloom, 1988), and between-system neuroadaptations, which refer to the recruitment of the brain 'antireward' stress systems during food withdrawal (Parylak et al, 2011).

Consumption of palatable food is hypothesized to result in within-system neuroadaptations through repeated stimulation, during which a form of sensitization of incentive salience initially occurs (Robinson and Berridge, 1993), and eventually desensitization of the mesolimbic dopamine system, therefore creating deficiencies in reward signaling. In populations with $\mathrm{BED}$ and obesity, there is evidence to 
support a hypofunctioning of the midbrain dopamine system (described below); however, no research has focused on directly linking this phenomenon to compulsive eating as opposed to bingeing. Balodis et al (2013a) found that binge eating individuals had lower striatal and prefrontal activation to anticipation of a monetary reward, and this decrease was associated with increased incidence of binge eating (Balodis et al, 2014). In animal models, high-fat and high-sugar diets induce alterations in dopaminergic system, such as downregulated dopamine 2 receptors (D2DRs) in the striatum (Colantuoni et al, 2001; Johnson and Kenny, 2010), reduced basal levels of dopamine in the NAc (Rada et al, 2010), and alterations in dopamine transport and turnover (Bello et al, 2003; Hajnal and Norgren, 2002). Over time, the once rewarding properties of the palatable food are diminished, reflecting a decrease in dopaminergic transmission in the ventral striatum (Bello et al, 2002; Bello et al, 2003; Hajnal and Norgren, 2002). Overeating may, therefore, reflect the need to reactivate a hypofunctional reward circuit (Geiger et al, 2009; Wang et al, 2001). However, it is important to note that dopaminergic signaling within striatal areas may be dynamic, where under certain experimental conditions, dopamine signaling in response to food bingeing-related cues remains high (Avena et al, 2008b; Corwin et al, 2011; Rada et al, 2005), resulting in a persistence of sensitization of incentive salience (Robinson and Berridge, 1993), despite a compromised reward system.

A key between-system neuroadaptation implicated in the emergence of a negative emotional withdrawal state is the recruitment of the stress systems in the extended amygdala. Although neuroimaging studies in humans have demonstrated increased amygdalar activation in response to highcalorie food-cues compared with low-calorie food cues (measured using fMRI; Stoeckel et al, 2008) and altered resting functional connectivity with cortical areas (Lips et al, 2014) in obese compared with lean subjects, much of what is known in its role in compulsive eating is from preclinical research. Specifically, animal studies have demonstrated neuroplasticity in these circuits including the recruitment of corticotropin-releasing factor (CRF) and its type-1 receptor (CRFR1) in the extended amygdala. The CRFCRFR1 system is a key player in mediating responses to stressors and it contributes to the maintenance and resumption of addictive behaviors (Koob et al, 2014; Koob and Zorrilla, 2010; Shalev et al, 2010). Extended access to drugs and palatable food engages the CRF-CRFR1 system (Cottone et al, 2009a; Iemolo et al, 2013; Koob and Zorrilla, 2010). During palatable food withdrawal, CRF expression and CRFR1 electrophysiological responsiveness is increased in the central amygdala (CeA), which are accompanied by withdrawal-dependent arousal and anxiety-like behavior. (Cottone et al, 2009a; Iemolo et al, 2013; Teegarden and Bale, 2007, 2008). Furthermore, selective CRFR1 antagonists block anxiety-like behavior seen during withdrawal from palatable food when directly administered into the CeA (Cottone et al, 2009a; Iemolo et al, 2013), and block stress-induced bingelike eating when administered into the bed nucleus of the stria terminalis (BNST; Micioni Di Bonaventura et al, 2014).

The recruitment of the brain stress systems in the extended amygdala is also accompanied by compensatory mechanisms to oppose these effects. The endocannabinoid system is considered one of several 'buffer systems', which acts to restore homeostasis to amygdalar circuits (Hillard et al, 2012; Koob, 2015; Sidhpura and Parsons, 2011). Withdrawal from palatable food increases the endocannabinoid 2arachidonoylglycerol and cannabinoid receptor 1 (CB1R) levels in the CeA (Blasio et al, 2013). Infusion of the CB1R inverse agonist rimonabant into the $\mathrm{CeA}$ precipitates anxiety-like behavior and anorexia during palatable food withdrawal (Blasio et al, 2013; Blasio et al, 2014a). We therefore hypothesize that the endocannabinoid system of the amygdala is recruited during withdrawal from palatable food as a compensatory mechanism to dampen anxiety. Thus, compelling evidence exists to argue that plasticity in the brain stress systems, a heretofore largely neglected component of addiction, is triggered by acute excessive drug/palatable food intake, is sensitized during repeated withdrawal, persists into protracted abstinence, and contributes to the development and persistence of addiction (Koob, 2013).

\section{OVEREATING DESPITE AVERSIVE CONSEQUENCES}

\section{Psychobehavioral Feature: Failure of Inhibitory Control}

Loss of control over food and drug seeking and taking behavior is considered an intractable aspect of addiction, resulting in continued use despite many incurring negative consequences under which behaviors would typically be suppressed (Deroche-Gamonet et al, 2004; Hopf and Lesscher, 2014; Rossetti et al, 2014; Vanderschuren and Everitt, 2004; Velazquez-Sanchez et al, 2014). Maladaptive eating behavior can result in medical conditions associated with weight gain as well as social impairment, emotional problems, and psychiatric disorders (Klatzkin et al, 2015; WHO, 2000; Warschburger, 2005). However, despite the many resulting negative consequences of the behavior, the individual finds it very difficult to stop. 'Loss of control' is thought to result from deficits in inhibitory control mechanisms responsible for the suppression of inappropriate actions. These deficits likely confer vulnerability to addictive behavior and/or emerge from persistent and prolonged drug use or palatable food overconsumption (Chen et al, 2013; Lubman et al, 2004; Volkow et al, 2013).

Individuals with disorders of compulsive eating behavior show poor performance on tasks of executive function and inhibitory control related to food, such as limiting responses, inhibiting cravings, or delay discounting (Batterink et al, 2010; Hege et al, 2015; Svaldi et al, 2014; Wu et al, 2013). These deficits are associated with further weight gain (PauliPott et al, 2010; Seeyave et al, 2009) and poorer response to weight loss treatment (Murdaugh et al, 2012). This loss of control overeating often persists despite the multitude of adverse events encompassing physical, psychological, and social problems that arise or are exacerbated by overeating. Individuals who compulsively overeat are, indeed, often plagued with distress following overeating, citing reactions of shame, denial, rationalization, and blaming, as well as feelings of a loss of control (Lyons, 1998). When these negative emotional and physical consequences outweigh the desirable effects of palatable food, people often attempt to diet and to avoid triggering foods (Curtis and Davis, 2014), even though most relapse into unhealthy eating habits (Halmi, 2013). 
Under this theoretical framework, compulsive-like behavior is operationalized in preclinical research as the obtainment of the search for a reward in spite of adverse conditions or consequences (Barnea-Ygael et al, 2012; Belin et al, 2008; Cottone et al, 2012; Smith et al, 2015; Vanderschuren and Everitt, 2004). Multiple paradigms have suggested that compulsive-like eating behavior can become evident following a history of palatable food consumption (ie, high in fat and/or sugar; Di Segni et al, 2014). For instance, animals display compulsive-like behavior such as continuing to consume palatable food even in the presence of mild electric shock (Rossetti et al, 2014) or a conditioned stimulus that signals an electric shock (Latagliata et al, 2010; Nieh et al, 2015; Velazquez-Sanchez et al, 2015). Animals will also continue to eat palatable food even when they must endure an aversive condition (ie, crossing a novel, bright, and potentially dangerous environment to obtain it; Calvez and Timofeeva, 2016; Cottone et al, 2012; Dore et al, 2014; Oswald et al, 2011) or working through a progressive ratio procedure where the cost of responding increases with each reward (Velazquez-Sanchez et al, 2014).

\section{Neurobiological Substrates: The Prefrontal Cortex}

Dysfunctions in multiple prefronto-striatal circuitries are hypothesized to underlie compulsive behaviors, and specifically loss of control. Within the PFC, two opposing systems are postulated: one which drives craving and re-engages habits (a 'GO' system; dorsolateral PFC (dlPFC), anterior cingulate, and orbitofrontal cortex), and one which instead inhibits this drive through the assessment of the incentive value of choices and suppression of emotional responses to stimuli (a 'STOP' system; ventromedial PFC (vmPFC); Koob and Volkow, 2016). In addictive disorders, these systems become unbalanced such that on one side PFC areas are hyperresponsive to food cues, whereas on the other side a general hypoactivation of prefrontal circuits involved in inhibitory control results in the disinhibition of the basal ganglia and stress systems of the amygdala (Koob and Volkow, 2016).

Cue-induced activation of $\mathrm{PFC}$ regions drives craving through functional connections with the striatum (Tomasi and Volkow, 2013). Both drug addicted and obese individuals show abnormal activation of PFC regions following cue-exposure, and this activation correlates with levels of elicited craving for drugs or food (Tomasi and Volkow, 2013; Volkow and Fowler, 2000; Volkow et al, 1993; Volkow et al, 2008b). In compulsive eating, this increased activation is thought to re-engage the basal ganglia circuitry involved in habitual overeating. Consistent with the above, a treatment approach directly targeting the dlPFC with transcranial direct current stimulation (tDCS) was shown to be effective in reducing craving for palatable food in binge eating women (anode right/cathode left, excitatory and inhibitory, respectively; Kekic et al, 2014). This effect of tDCS may be effectively attenuating the 'cue-induced craving' circuit modulated by the dorsolateral PFC, or alternatively, through boosting inhibitory control systems by its connectivity to the vmPFC (Hare et al, 2014).

In BED, PFC dysregulation is associated with deficits in inhibitory control (Balodis et al, 2013b; Boeka and Lokken, 2011; Hege et al, 2015). In addition, diminished activation of
vmPFC during an inhibitory control task was associated with impaired dietary restraint in obese individuals with BED, but not in obese controls (Balodis et al, 2013b). A study using positron emission topography observed decreased glucose metabolism in prefrontal areas of obese populations, which correlated with lower D2DR striatal levels (Volkow et al, 2008b). As lower amounts of D2DRs in the striatum are associated with lower inhibitory control (ie, higher impulsivity; Klein et al, 2007), it is hypothesized that these deficits in PFC activity may cause disinhibition of impulsivity circuits in the ventral striatum (Volkow et al, 2008b; for further review see (Kessler et al, 2016).

Modulation of the mPFC glutamatergic projections (both the 'GO' and 'STOP' systems) is a promising therapeutic target for compulsive eating. For example, $\mu$-opioid antagonists have been shown to reduce attentional biases for food cues (Chamberlain et al, 2012). Memantine (an N-methyl-Daspartate glutamate receptor (NMDAR) uncompetitive antagonist) was found to reduce binge eating as well as 'disinhibition' of eating behaviors (Brennan et al, 2008). Memantine has also been shown to reduce impulsivity and enhance cognitive control in compulsive shoppers (Grant et al, 2012), a proposed behavioral addiction. Furthermore, Sigma 1-receptors, though not yet tested in humans, are regarded as a promising target for addiction, among other psychiatric disorders, and are known to modulate the PFC glutamatergic system (Alonso et al, 2000; Dong et al, 2007; Hayashi et al, 2011).

Animal models have demonstrated the involvement of prefrontal $\mu$-opioid receptors, Sig1Rs, NMDARs, and recently the trace amine-associated receptor-1 (TAAR1) in compulsive-like eating behavior (Blasio et al, 2014b; Ferragud et al, 2016; Selleck et al, 2015; Smith et al, 2015; Velazquez-Sanchez et al, 2014). Specifically, using a model of compulsive-like eating (Cottone et al, 2012), limited access to a highly palatable diet increased levels of the gene coding for the opioid peptide pro-opiomelanocortin and suppressed the expression of the pro-dynorphin gene in the MPFC; and administration of the opioid antagonist naltrexone directly into the mPFC-reduced binge-like eating (Blasio et al, $2014 \mathrm{~b}$ ). These effects are thought to be driven by modulation of inhibitory control, likely through effects of PFC opioids on glutamatergic signaling to NAc targets (Mena et al, 2011; Mena et al, 2013; Selleck et al, 2015).

Sig1Rs, known to modulate alcohol and drug reinforcement (Blasio et al, 2015; Robson et al, 2012; Sabino et al, 2011; Sabino et al, 2009a; Sabino et al, 2009b), also appear to mediate compulsive-like eating in animal models. Limited access to palatable food increases Sig1R expression levels in prefronto-cortical regions of the brain, and systemic administration of BD-1063, a Sig1R antagonist, decreased compulsive-like eating (Cottone et al, 2012). Similarly, TAAR1 receptors, a system associated with inhibitory control and cognitive functioning (Espinoza et al, 2015a), were downregulated in the MPFC following binge-like eating, and TAAR1 agonist infusion into the infralimbic cortex blocked compulsive-like, binge eating (Ferragud et al, 2016). Both the Sig1R and TAAR1 systems in the mPFC may, therefore, influence glutamatergic signaling in cortico-striatal pathways, each contributing to compulsive-like behavior (Cottone et al, 2012; Dong et al, 2007; Espinoza et al, 2015b; Kalivas and Volkow, 2005). Accordingly, systemic treatment 
with NMDAR uncompetitive antagonist memantine blocks compulsive-like eating and microinfusion of memantine directly into the NAc reduces binge-like eating (Smith et al, 2015).

Thus, it is likely that two mechanisms intersect in the frontal cortex to contribute to compulsive eating: prefrontal circuits re-engage striatal regions to activate craving (see habitual overeating section above), and dysregulation of prefrontal circuits produces disinhibition of both impulsive acts (via the basal ganglia) and stress reactions (via the extended amygdala; see overeating to relieve an negative emotional state section above).

\section{DISCUSSION}

As described above, compulsive eating behavior is a pathological form of feeding that phenotypically, neurobiologically, and conceptually resembles compulsive behavior associated with both drugs of abuse and behavioral addictions. Preclinical research on feeding, represented largely by studies on obesity, has been hampered by the predominant classical view of eating as a mere energyhomeostatic behavior, ignoring forms of overeating that are compulsive in nature. This limited view has hindered methodological advances on more complex behavioral expressions of pathological feeding and, in turn, on our understanding of the underlying neurobiological substrates. However, it should be noted that eating behavior is under control of multiple mechanisms (often compartmentalized in homeostatic and hedonic components), which are far from independent, and thus cannot be studied without consideration of the other. Although the study of the interaction of these two components in relation to the study of basic eating processes has been rapidly increasing in the scientific community, a bigger effort will be needed to investigate it in the context of compulsive eating.

The parallels drawn between drugs of abuse and food have led to the question of whether forms of compulsive eating in human and animal subjects may predispose to compulsive drug use and vice versa. Few studies have suggested significant overlap between compulsive drug use and disorders characterized by compulsive eating; for example, there is data of an increased prevalence of substance abuse disorders in individuals with BED (Javaras et al, 2008). Evidence in obesity is instead mixed, with some studies showing positive associations (Arif and Rohrer, 2005; Petry et al, 2008) and others negative associations (John et al, 2005; Simon et al, 2006) between alcohol use disorders and obesity. This discrepancy could be explained by the heterogeneity of obesity populations, such that only certain subgroups are at risk (Sansone and Sansone, 2013). Preclinical research in this context is still in its infancy, and studies have mostly focused on the effects of overeating or obesity induced by exposure to highly palatable foods (rather than compulsive-like eating per se) on drug-related behavior (rather than compulsive-like drug use per se). Indeed, in animal models of obesity and/or binge eating there is some evidence of vulnerability factors for the development of compulsive drug taking in the form of brain reward deficits (Valenza et al, 2015) that increased alcohol self-administration (Avena et al, 2004), and greater cocaine craving (Barnea et al, 2015). However, much more research is needed to understand the relationship between compulsive drug use and compulsive eating.

Investigations into the neurobiology of drugs of abuse and highly palatable foods have lent a solid theoretical foundation for how reward, stress, and cognitive function neurocircuitries may be disrupted and ultimately drive compulsive eating behavior. The evidence described here supports the hypothesis that palatable food consumption may initially activate the mesolimbic dopamine incentive salience pathways, and then, repeated, over-stimulations may lead to a cascade of neurobehavioral adaptations, including a shift to dorsal striatal-mediated habitual behavior, desensitization of the reward system, recruitment of the amygdaloid stress systems, and loss of prefronto-cortical control over behavior. However, these neurobiological mechanisms have many further complexities (eg, diet effects on dopamine systems; Baladi et al, 2012) that framed in the context of compulsive eating could serve as the topic of a future review.

It is necessary to further our understanding of the interactions of these maladaptive circuits and how compulsive eating behavior differs from non-pathological eating. Functionally anchored animal models of compulsive eating behaviors are also needed to bring the field to this next level through the integration of these elements (ie, habitual/ inflexible feeding responding, negatively reinforced feeding, and eating in spite of negative consequences). One caveat is that the use of animal models has intrinsic limitations, especially when complex psychiatric disorders are modeled; for example, the utilization of specific controlled environmental conditions such as differential access to experimental diets (eg, intermittent $v s$ continuous). Many factors (history and schedule of diet access, composition of diet, behavioral assessments of compulsivity) contribute to the percentages of animals that reliably display compulsive-like eating behavior (de Jong et al, 2013; Heyne et al, 2009; Parylak et al, 2012). The details of experimental conditions associated with compulsive-like eating behavior are extensive, and could serve its own topic in a future review. Despite some inherent limitations, innovative animal models of functionally anchored behaviors reflecting specific endophenotypes of psychiatric syndromes will prove indispensable to understand the neurobiological underpinnings of a disorder, and for the discovery of novel pharmacological treatments.

A deeper understanding of the mechanisms behind each of the elements can shed light on the underlying pathology of compulsive eating behavior, and can also explain its pathogenesis. Currently, there are substantial gaps in the knowledge of the emergence and time course of these elements of compulsive eating, which hold potential for providing essential information for preventative measures and therapeutic targets for these conditions. Furthermore, by focusing on all of the elements, as opposed to each separately, we can start to understand the interactions of these areas and related neurocircuitries, identifying how the elements may influence each other (eg, relationships between depression/stress on learning and decision-making processes). Such an approach will provide the evidence-based data for understanding individual differences and resonate well with the spirit of new initiatives in precision medicine. Retuning both conceptual and the methodological approaches to compulsive eating will be essential to gain a 
better understanding diagnosis, prevention, and treatment of pathological eating.

\section{FUNDING AND DISCLOSURE}

This work was supported by grants DA030425 (PC), MH091945 (PC), MH093650 (VS), and AA024439 (VS) from NIDA, NIMH, and NIAAA by the Peter Paul Career Development Professorship (PC), the McManus Charitable Trust (VS), the Burroughs Wellcome Fund through the Transformative Training Program in Addiction Sciences (CFM). The authors declare no conflict of interest.

\section{DISCLAIMER}

The contents are solely the responsibility of the authors and do not necessarily represent the official views of the National Institutes of Health.

\section{REFERENCES}

Agh T, Kovacs G, Supina D, Pawaskar M, Herman BK, Voko Z et al (2016). A systematic review of the health-related quality of life and economic burdens of anorexia nervosa, bulimia nervosa, and binge eating disorder. Eat Weight Disord 21: 353-364.

Alonso G, Phan V, Guillemain I, Saunier M, Legrand A, Anoal M et al (2000). Immunocytochemical localization of the sigma(1) receptor in the adult rat central nervous system. Neuroscience $\mathbf{9 7}$ : 155-170.

American Psychiatric Association (2000). Diagnostic and Statistical Manual of Mental Disorders IV-TR ed edn. American Psychiatric Publishing.

American Psychiatric Association (2013). Diagnostic and Statistical Manual of Mental Disorders (5th edn.) American Psychiatric Publishing.

Arif AA, Rohrer JE (2005). Patterns of alcohol drinking and its association with obesity: data from the Third National Health and Nutrition Examination Survey, 1988-1994. BMC Public Health 5: 126.

Avena NM, Bocarsly ME, Rada P, Kim A, Hoebel BG (2008a). After daily bingeing on a sucrose solution, food deprivation induces anxiety and accumbens dopamine/acetylcholine imbalance. Physiol Behav 94: 309-315.

Avena NM, Carrillo CA, Needham L, Leibowitz SF, Hoebel BG (2004). Sugar-dependent rats show enhanced intake of unsweetened ethanol. Alcohol 34: 203-209.

Avena NM, Rada P, Hoebel BG (2008b). Evidence for sugar addiction: behavioral and neurochemical effects of intermittent, excessive sugar intake. Neurosci Biobehav Rev 32: 20-39.

Babbs RK, Sun X, Felsted J, Chouinard-Decorte F, Veldhuizen MG, Small DM (2013). Decreased caudate response to milkshake is associated with higher body mass index and greater impulsivity. Physiol Behav 121: 103-111.

Baladi MG, Daws LC, France CP (2012). You are what you eat: influence of type and amount of food consumed on central dopamine systems and the behavioral effects of direct- and indirect-acting dopamine receptor agonists. Neuropharmacology 63: 76-86.

Balodis IM, Grilo CM, Kober H, Worhunsky PD, White MA, Stevens MC et al (2014). A pilot study linking reduced frontoStriatal recruitment during reward processing to persistent bingeing following treatment for binge-eating disorder. Int J Eat Disord 47: 376-384.

Balodis IM, Kober H, Worhunsky PD, White MA, Stevens MC, Pearlson GD et al (2013a). Monetary reward processing in obese individuals with and without binge eating disorder. Biol Psychiatry 73: 877-886.

Balodis IM, Molina ND, Kober H, Worhunsky PD, White MA, Rajita S et al (2013b). Divergent neural substrates of inhibitory control in binge eating disorder relative to other manifestations of obesity. Obesity 21: 367-377.

Barnea-Ygael N, Yadid G, Yaka R, Ben-Shahar O, Zangen A (2012). Cue-induced reinstatement of cocaine seeking in the rat "conflict model": effect of prolonged home-cage confinement. Psychopharmacology 219: 875-883.

Barnea R, Bekker L, Zifman N, Marco A, Yadid G, Weller A (2015). Trait and state binge eating predispose towards cocaine craving. Addict Biol (e-pub ahead of print; doi:10.1111/adb.12315).

Batterink L, Yokum S, Stice E (2010). Body mass correlates inversely with inhibitory control in response to food among adolescent girls: an fMRI study. Neuroimage 52: 1696-1703.

Belin-Rauscent A, Fouyssac M, Bonci A, Belin D (2015). How preclinical models evolved to resemble the diagnostic criteria of drug addiction. Biol Psychiatry 79: 39-46.

Belin D, Everitt BJ (2008). Cocaine seeking habits depend upon dopamine-dependent serial connectivity linking the ventral with the dorsal striatum. Neuron 57: 432-441.

Belin D, Mar AC, Dalley JW, Robbins TW, Everitt BJ (2008). High impulsivity predicts the switch to compulsive cocaine-taking. Science 320: 1352-1355.

Bello NT, Lucas LR, Hajnal A (2002). Repeated sucrose access influences dopamine D2 receptor density in the striatum. Neuroreport 13: 1575-1578.

Bello NT, Sweigart KL, Lakoski JM, Norgren R, Hajnal A (2003). Restricted feeding with scheduled sucrose access results in an upregulation of the rat dopamine transporter. Am J Physiol Regul Integr Comp Physiol 284: R1260-R1268.

Berlin GS, Hollander E (2014). Compulsivity, impulsivity, and the DSM-V process. CNS Spectr 19: 62-68.

Blasio A, Iemolo A, Sabino V, Petrosino S, Steardo L, Rice KC et al (2013). Rimonabant precipitates anxiety in rats withdrawn from palatable food: role of the central amygdala. Neuropsychopharmacology 38: 2498-2507.

Blasio A, Rice KC, Sabino V, Cottone P (2014a). Characterization of a shortened model of diet alternation in female rats: effects of the $\mathrm{CB} 1$ receptor antagonist rimonabant on food intake and anxietylike behavior. Behav Pharmacol 25: 609-617.

Blasio A, Steardo L, Sabino V, Cottone P (2014b). Opioid system in the medial prefrontal cortex mediates binge-like eating. Addict Biol 19: 652-662.

Blasio A, Valenza M, Iyer MR, Rice KC, Steardo L, Hayashi T et al (2015). Sigma-1 receptor mediates acquisition of alcohol drinking and seeking behavior in alcohol-preferring rats. Behav Brain Res 287: 315-322.

Boeka AG, Lokken KL (2011). Prefrontal systems involvement in binge eating. Eat Weight Disord 16: e121-e126.

Brennan BP, Roberts JL, Fogarty KV, Reynolds KA, Jonas JM, Hudson JI (2008). Memantine in the treatment of binge eating disorder: an open-label, prospective trial. Int J Eat Disord 41: 520-526.

Bruch H (1973). Eating Disorders; Obesity, Anorexia Nervosa, and the Person Within. Basic Books: New York, xp 396.

Calvez J, Timofeeva E (2016). Behavioral and hormonal responses to stress in binge-like eating prone female rats. Physiol Behav 157: 28-38.

Carr KD (2016). Nucleus accumbens AMPA receptor trafficking upregulated by food restriction: an unintended target for drugs of abuse and forbidden foods. Curr Opin Behav Sci 9: 32-39.

Chamberlain SR, Mogg K, Bradley BP, Koch A, Dodds CM, Tao WX et al (2012). Effects of mu opioid receptor antagonism on cognition in obese binge-eating individuals. Psychopharmacology 224: 501-509.

Chen BT, Yau HJ, Hatch C, Kusumoto-Yoshida I, Cho SL, Hopf FW et al (2013). Rescuing cocaine-induced prefrontal 
cortex hypoactivity prevents compulsive cocaine seeking. Nature 496: 359-362.

Clark MM, Niaura R, King TK, Pera V (1996). Depression, smoking, activity level, and health status: pretreatment predictors of attrition in obesity treatment. Addict Behav 21: 509-513.

Colantuoni C, Rada P, McCarthy J, Patten C, Avena NM, Chadeayne A et al (2002). Evidence that intermittent, excessive sugar intake causes endogenous opioid dependence. Obes Res 10: 478-488.

Colantuoni C, Schwenker J, McCarthy J, Rada P, Ladenheim B, Cadet JL et al (2001). Excessive sugar intake alters binding to dopamine and mu-opioid receptors in the brain. Neuroreport 12: 3549-3552.

Corbit LH (2016). Effects of obesogenic diets on learning and habitual responding. Curr Opin Behav Sci 9: 84-90.

Corbit LH, Nie H, Janak PH (2012). Habitual alcohol seeking: time course and the contribution of subregions of the dorsal striatum. Biol Psychiatry 72: 389-395.

Corwin RL, Avena NM, Boggiano MM (2011). Feeding and reward: perspectives from three rat models of binge eating. Physiol Behav 104: 87-97.

Cottone P, Sabino V, Roberto M, Bajo M, Pockros L, Frihauf JB et al (2009a). CRF system recruitment mediates dark side of compulsive eating. Proc Natl Acad Sci USA 106: 20016-20020.

Cottone P, Sabino V, Steardo L, Zorrilla EP (2008). Opioiddependent anticipatory negative contrast and binge-like eating in rats with limited access to highly preferred food. Neuropsychopharmacology 33: 524-535.

Cottone P, Sabino V, Steardo L, Zorrilla EP (2009b). Consummatory, anxiety-related and metabolic adaptations in female rats with alternating access to preferred food. Psychoneuroendocrinology 34: 38-49.

Cottone P, Wang X, Park JW, Valenza M, Blasio A, Kwak J et al (2012). Antagonism of sigma-1 receptors blocks compulsivelike eating. Neuropsychopharmacology 37: 2593-2604.

Curtis C, Davis C (2014). A qualitative study of binge eating and obesity from an addiction perspective. Eat Disord 22: 19-32.

Dallman MF, Pecoraro N, Akana SF, La Fleur SE, Gomez F, Houshyar $\mathrm{H}$ et al (2003). Chronic stress and obesity: a new view of "comfort food". Proc Natl Acad Sci USA 100: 11696-11701.

Davis C (2013). A narrative review of binge eating and addictive behaviors: shared associations with seasonality and personality factors. Front Psychiatry 4: 183 .

Davis C, Carter JC (2009). Compulsive overeating as an addiction disorder. A review of theory and evidence. Appetite 53: 1-8.

Davis C, Curtis C, Levitan RD, Carter JC, Kaplan AS, Kennedy JL (2011). Evidence that 'food addiction' is a valid phenotype of obesity. Appetite 57: 711-717.

Day JJ, Roitman MF, Wightman RM, Carelli RM (2007). Associative learning mediates dynamic shifts in dopamine signaling in the nucleus accumbens. Nat Neurosci 10: 1020-1028.

de Jong JW, Meijboom KE, Vanderschuren LJ, Adan RA (2013). Low control over palatable food intake in rats is associated with habitual behavior and relapse vulnerability: individual differences. PLoS One 8: e74645.

de Zwaan M (2001). Binge eating disorder and obesity. Int J Obes Relat Metabol Disord 25(Suppl 1): S51-S55.

Deroche-Gamonet V, Belin D, Piazza PV (2004). Evidence for addiction-like behavior in the rat. Science 305: 1014-1017.

Di Segni M, Patrono E, Patella L, Puglisi-Allegra S, Ventura R (2014). Animal models of compulsive eating behavior. Nutrients 6: 4591-4609.

Dickerson JF, DeBar L, Perrin NA, Lynch F, Wilson GT, Rosselli F et al (2011). Health-service use in women with binge eating disorders. Int J Eat Disord 44: 524-530.

Dingemans AE, van Furth EF (2012). Binge eating disorder psychopathology in normal weight and obese individuals. Int $J$ Eat Disord 45: 135-138.
Dong LY, Cheng ZX, Fu YM, Wang ZM, Zhu YH, Sun JL et al (2007). Neurosteroid dehydroepiandrosterone sulfate enhances spontaneous glutamate release in rat prelimbic cortex through activation of dopamine D1 and sigma-1 receptor. Neuropharmacology 52: 966-974.

Dore R, Valenza M, Wang X, Rice KC, Sabino V, Cottone P (2014). The inverse agonist of CB1 receptor SR141716 blocks compulsive eating of palatable food. Addict Biol 19: 849-861.

el-Guebaly N, Mudry T, Zohar J, Tavares H, Potenza MN (2012). Compulsive features in behavioural addictions: the case of pathological gambling. Addiction 107: 1726-1734.

Eldredge K, Wilson T, Whaley A (1990). Failure, self-evaluation, and feeling fat in women. Int J Eat Disorder 9: 37-50.

Epstein LH, Temple JL, Roemmich JN, Bouton ME (2009). Habituation as a determinant of human food intake. Psychol Rev 116: 384-407.

Espinoza S, Ghisi V, Emanuele M, Leo D, Sukhanov I, Sotnikova TD et al (2015a). Postsynaptic D2 dopamine receptor supersensitivity in the striatum of mice lacking TAAR1. Neuropharmacology 93: 308-313.

Espinoza S, Lignani G, Caffino L, Maggi S, Sukhanov I, Leo D et al (2015b). TAAR1 modulates cortical glutamate NMDA receptor function. Neuropsychopharmacology 40: 2217-2227.

Everitt BJ (2014). Neural and psychological mechanisms underlying compulsive drug seeking habits and drug memoriesindications for novel treatments of addiction. Eur J Neurosci 40: 2163-2182.

Everitt BJ, Robbins TW (2000). Second-order schedules of drug reinforcement in rats and monkeys: measurement of reinforcing efficacy and drug-seeking behaviour. Psychopharmacology 153: 17-30.

Everitt BJ, Robbins TW (2005). Neural systems of reinforcement for drug addiction: from actions to habits to compulsion. Nat Neurosci 8: 1481-1489.

Everitt BJ, Robbins TW (2013). From the ventral to the dorsal striatum: devolving views of their roles in drug addiction. Neurosci Biobehav Rev 37(9 Pt A): 1946-1954.

Everitt BJ, Robbins TW (2016). Drug addiction: updating actions to habits to compulsions ten years on. Annu Rev Psychol 67: 23-50.

Ferragud A, Howell AD, Moore CF, Ta TL, Hoener MC, Sabino V et al (2016). The trace amine-associated receptor 1 agonist RO5256390 blocks compulsive, binge-like eating in rats. Neuropsychopharmacology (e-pub ahead of print; doi:10.1038/ npp.2016.233).

Finkelstein EA, Trogdon JG, Cohen JW, Dietz W (2009). Annual medical spending attributable to obesity: payer-and servicespecific estimates. Health Aff 28: w822-w831.

Fontaine KR, Barofsky I (2001). Obesity and health-related quality of life. Obes Rev 2: 173-182.

Furlong TM, Jayaweera HK, Balleine BW, Corbit LH (2014). Bingelike consumption of a palatable food accelerates habitual control of behavior and is dependent on activation of the dorsolateral striatum. J Neurosci 34: 5012-5022.

Galanti K, Gluck ME, Geliebter A (2007). Test meal intake in obese binge eaters in relation to impulsivity and compulsivity. Int $J$ Eat Disord 40: 727-732.

Garcia-Garcia I, Narberhaus A, Marques-Iturria I, Garolera M, Radoi A, Segura B et al (2013). Neural responses to visual food cues: insights from functional magnetic resonance imaging. Eur Eat Disord Rev 21: 89-98.

Gearhardt AN, Corbin WR, Brownell KD (2009). Preliminary validation of the Yale Food Addiction Scale. Appetite 52: 430-436.

Gearhardt AN, Corbin WR, Brownell KD (2016). Development of the Yale Food Addiction Scale Version 2.0. Psychol Addict Behav 30: $113-121$.

Gearhardt AN, White MA, Masheb RM, Morgan PT, Crosby RD, Grilo CM (2012). An examination of the food addiction construct in obese patients with binge eating disorder. Int J Eat Disord 45: $657-663$. 
Geiger BM, Haburcak M, Avena NM, Moyer MC, Hoebel BG, Pothos EN (2009). Deficits of mesolimbic dopamine neurotransmission in rat dietary obesity. Neuroscience 159: 1193-1199.

George O, Koob GF, Vendruscolo LF (2014). Negative reinforcement via motivational withdrawal is the driving force behind the transition to addiction. Psychopharmacology 231: 3911-3917.

Giuliano C, Cottone P (2015). The role of the opioid system in binge eating disorder. CNS Spectr 20: 537-545.

Giuliano C, Robbins TW, Nathan PJ, Bullmore ET, Everitt BJ (2012). Inhibition of opioid transmission at the mu-opioid receptor prevents both food seeking and binge-like eating. Neuropsychopharmacology 37: 2643-2652.

Gonzalez VM, Vitousek KM (2004). Feared food in dieting and non-dieting young women: a preliminary validation of the Food Phobia Survey. Appetite 43: 155-173.

Grant JE, Odlaug BL, Mooney M, O'Brien R, Kim SW (2012). Openlabel pilot study of memantine in the treatment of compulsive buying. Ann Clin Psychiatry 24: 119-126.

Greeno CG, Wing RR (1994). Stress-induced eating. Psychol Bull 115: 444-464.

Hajnal A, Norgren R (2002). Repeated access to sucrose augments dopamine turnover in the nucleus accumbens. Neuroreport 13: 2213-2216.

Halbout B, Liu AT, Ostlund SB (2016). A closer look at the effects of repeated cocaine exposure on adaptive decision-making under conditions that promote goal-directed control. Front Psychiatry 7: 44 .

Halfon N, Larson K, Slusser W (2013). Associations between obesity and comorbid mental health, developmental, and physical health conditions in a nationally representative sample of US children aged 10 to 17. Acad Pediatr 13: 6-13.

Halmi KA (2013). Perplexities of treatment resistance in eating disorders. BMC Psychiatry 13: 292.

Hare TA, Hakimi S, Rangel A (2014). Activity in dlPFC and its effective connectivity to vmPFC are associated with temporal discounting. Front Neurosci 8: 50.

Hayashi T, Tsai SY, Mori T, Fujimoto M, Su TP (2011). Targeting ligand-operated chaperone sigma-1 receptors in the treatment of neuropsychiatric disorders. Expert Opin Ther Targets 15: 557-577.

Heatherton TF, Herman CP, Polivy J (1991). Effects of physical threat and ego threat on eating behavior. J Pers Soc Psychol 60: 138-143.

Hege MA, Stingl KT, Kullmann S, Schag K, Giel KE, Zipfel S et al (2015). Attentional impulsivity in binge eating disorder modulates response inhibition performance and frontal brain networks. Int J Obes 39: 353-360.

Hendrikse JJ, Cachia RL, Kothe EJ, McPhie S, Skouteris H, Hayden MJ (2015). Attentional biases for food cues in overweight and individuals with obesity: a systematic review of the literature. Obes Rev 16: 424-432.

Heyne A, Kiesselbach C, Sahun I, McDonald J, Gaiffi M, Dierssen $M$ et al (2009). An animal model of compulsive foodtaking behaviour. Addict Biol 14: 373-383.

Hillard CJ, Weinlander KM, Stuhr KL (2012). Contributions of endocannabinoid signaling to psychiatric disorders in humans: genetic and biochemical evidence. Neuroscience 204: 207-229.

Hone-Blanchet A, Fecteau S (2014). Overlap of food addiction and substance use disorders definitions: analysis of animal and human studies. Neuropharmacology 85: 81-90.

Hopf FW, Lesscher HM (2014). Rodent models for compulsive alcohol intake. Alcohol 48: 253-264.

Horstmann A, Dietrich A, Mathar D, Possel M, Villringer A, Neumann J (2015). Slave to habit? obesity is associated with decreased behavioural sensitivity to reward devaluation. Appetite 87: 175-183.

Iemolo A, Blasio A St, Cyr SA, Jiang F, Rice KC, Sabino V et al (2013). CRF-CRF1 receptor system in the central and basolateral nuclei of the amygdala differentially mediates excessive eating of palatable food. Neuropsychopharmacology 38: 2456-2466.

Iemolo A, Valenza M, Tozier L, Knapp CM, Kornetsky C, Steardo L et al (2012). Withdrawal from chronic, intermittent access to a highly palatable food induces depressive-like behavior in compulsive eating rats. Behav Pharmacol 23: 593-602.

Javaras KN, Pope HG, Lalonde JK, Roberts JL, Nillni YI, Laird NM et al (2008). Co-occurrence of binge eating disorder with psychiatric and medical disorders. J Clin Psychiatry 69: 266-273.

John U, Meyer C, Rumpf HJ, Hapke U (2005). Relationships of psychiatric disorders with overweight and obesity in an adult general population. Obes Res 13: 101-109.

Johnson PM, Kenny PJ (2010). Dopamine D2 receptors in addiction-like reward dysfunction and compulsive eating in obese rats. Nat Neurosci 13: 635-641.

Kagan D, Squires R (1983). Dieting, compulsive eating, and feelings of failure among adolescents. Int J Eat Disorder 3: 15-26.

Kalivas PW, Volkow ND (2005). The neural basis of addiction: a pathology of motivation and choice. Am J Psychiatry 162: 1403-1413.

Kaplan HI, Kaplan HS (1957). The psychosomatic concept of obesity. J Nerv Ment Dis 125: 181-201.

Kekic M, McClelland J, Campbell I, Nestler S, Rubia K, David AS et al (2014). The effects of prefrontal cortex transcranial direct current stimulation (tDCS) on food craving and temporal discounting in women with frequent food cravings. Appetite 78: 55-62.

Kessler RC, Berglund PA, Chiu WT, Deitz AC, Hudson JI, Shahly V et al (2013). The prevalence and correlates of binge eating disorder in the World Health Organization World Mental Health Surveys. Biol Psychiatry 73: 904-914.

Kessler RM, Hutson PH, Herman BK, Potenza MN (2016). The neurobiological basis of binge-eating disorder. Neurosci Biobehav Rev 63: 223-238.

Keys A, Brozek J, Henschel A, Mickelson O, Taylor H (1950). The Biology of Human Starvation. University of Minnesota Press: Minneapolis, MN.

Klatzkin RR, Gaffney S, Cyrus K, Bigus E, Brownley KA (2015). Binge eating disorder and obesity: preliminary evidence for distinct cardiovascular and psychological phenotypes. Physiol Behav 142: 20-27.

Klein TA, Neumann J, Reuter M, Hennig J, von Cramon DY, Ullsperger M (2007). Genetically determined differences in learning from errors. Science 318: 1642-1645.

Koob G, Volkow N (2016). Neurobiology of addiction: a neurocircuitry analysis. Lancet Psychiatry 3: 760-773.

Koob GF (1996). Drug addiction: the yin and yang of hedonic homeostasis. Neuron 16: 893-896.

Koob GF (1999). The role of the striatopallidal and extended amygdala systems in drug addiction. Ann NY Acad Sci 877: 445-460.

Koob GF (2009). Neurobiological substrates for the dark side of compulsivity in addiction. Neuropharmacology 56(Suppl 1): 18-31.

Koob GF (2013). Addiction is a reward deficit and stress surfeit disorder. Front Psychiatry 4: 72.

Koob GF (2015). The dark side of emotion: the addiction perspective. Eur J Pharmacol 753: 73-87.

Koob GF, Bloom FE (1988). Cellular and molecular mechanisms of drug dependence. Science 242: 715-723.

Koob GF, Buck CL, Cohen A, Edwards S, Park PE, Schlosburg JE et al (2014). Addiction as a stress surfeit disorder. Neuropharmacology 76(Pt B): 370-382.

Koob GF, Caine SB, Parsons L, Markou A, Weiss F (1997). Opponent process model and psychostimulant addiction. Pharmacol Biochem Behav 57: 513-521. 
Koob GF, Le Moal M (2001). Drug addiction, dysregulation of reward, and allostasis. Neuropsychopharmacology 24: 97-129.

Koob GF, Le Moal M (2008). Addiction and the brain antireward system. Annual Rev Psychol 59: 29-53.

Koob GF, Volkow ND (2010). Neurocircuitry of addiction. Neuropsychopharmacology 35: 217-238.

Koob GF, Zorrilla EP (2010). Neurobiological mechanisms of addiction: focus on corticotropin-releasing factor. Curr Opin Investig Drugs 11: 63-71.

Kwako LE, Momenan R, Litten RZ, Koob GF, Goldman D (2016). Addictions neuroclinical assessment: a neuroscience-based framework for addictive disorders. Biol Psychiatry 80: 179-189.

Latagliata EC, Patrono E, Puglisi-Allegra S, Ventura R (2010). Food seeking in spite of harmful consequences is under prefrontal cortical noradrenergic control. BMC Neurosci 11: 15.

Lawrence NS, Hinton EC, Parkinson JA, Lawrence AD (2012). Nucleus accumbens response to food cues predicts subsequent snack consumption in women and increased body mass index in those with reduced self-control. Neuroimage 63: 415-422.

Linde JA, Jeffery RW, Levy RL, Sherwood NE, Utter J, Pronk NP et al (2004). Binge eating disorder, weight control self-efficacy, and depression in overweight men and women. Int J Obes Relat Metab Disord 28: 418-425.

Lingawi NW, Balleine BW (2012). Amygdala central nucleus interacts with dorsolateral striatum to regulate the acquisition of habits. J Neurosci 32: 1073-1081.

Lips MA, Wijngaarden MA, van der Grond J, van Buchem MA, de Groot GH, Rombouts SA et al (2014). Resting-state functional connectivity of brain regions involved in cognitive control, motivation, and reward is enhanced in obese females. Am J Clin Nutr 100: 524-531.

Lubman DI, Yucel M, Pantelis C (2004). Addiction, a condition of compulsive behaviour? Neuroimaging and neuropsychological evidence of inhibitory dysregulation. Addiction 99: 1491-1502.

Lucantonio F, Caprioli D, Schoenbaum G (2014). Transition from 'model-based' to 'model-free' behavioral control in addiction: involvement of the orbitofrontal cortex and dorsolateral striatum. Neuropharmacology 76(Pt B): 407-415.

Lyons MA (1998). The phenomenon of compulsive overeating in a selected group of professional women. J Adv Nurs 27: 1158-1164.

Macht M (2008). How emotions affect eating: a five-way model. Appetite 50: 1-11.

Mancino S, Burokas A, Gutierrez-Cuesta J, Gutierrez-Martos M, Martin-Garcia E, Pucci M et al (2015). Epigenetic and proteomic expression changes promoted by eating addictive-like behavior. Neuropsychopharmacology 40: 2788-2800.

Mann T, Tomiyama AJ, Westling E, Lew AM, Samuels B, Chatman J (2007). Medicare's search for effective obesity treatments: diets are not the answer. Am Psychol 62: 220-233.

McGuire MT, Wing RR, Klem ML, Lang W, Hill JO (1999). What predicts weight regain in a group of successful weight losers? J Consult Clin Psychol 67: 177-185.

Mena JD, Sadeghian K, Baldo BA (2011). Induction of hyperphagia and carbohydrate intake by mu-opioid receptor stimulation in circumscribed regions of frontal cortex. J Neurosci 31: 3249-3260.

Mena JD, Selleck RA, Baldo BA (2013). Mu-opioid stimulation in rat prefrontal cortex engages hypothalamic orexin/hypocretincontaining neurons, and reveals dissociable roles of nucleus accumbens and hypothalamus in cortically driven feeding. J Neurosci 33: 18540-18552.

Meule A, Lutz A, Vogele C, Kubler A (2012). Women with elevated food addiction symptoms show accelerated reactions, but no impaired inhibitory control, in response to pictures of highcalorie food-cues. Eat Behav 13: 423-428.

Micioni Di Bonaventura MV, Ciccocioppo R, Romano A, Bossert JM, Rice KC, Ubaldi M et al (2014). Role of bed nucleus of the stria terminalis corticotrophin-releasing factor receptors in frustration stress-induced binge-like palatable food consumption in female rats with a history of food restriction. J Neurosci 34: $11316-11324$.

Murdaugh DL, Cox JE, Cook EW 3rd, Weller RE (2012). fMRI reactivity to high-calorie food pictures predicts short- and longterm outcome in a weight-loss program. Neuroimage 59: 2709-2721.

Nair SG, Adams-Deutsch T, Epstein DH, Shaham Y (2009). The neuropharmacology of relapse to food seeking: methodology, main findings, and comparison with relapse to drug seeking. Prog Neurobiol 89: 18-45.

The National Institute of Mental Health (2013). Research Domain Criteria (RDoC). https://www.nimh.nih.gov/research-priorities/ rdoc/index.shtml.

Nieh EH, Matthews GA, Allsop SA, Presbrey KN, Leppla CA, Wichmann $\mathrm{R}$ et al (2015). Decoding neural circuits that control compulsive sucrose seeking. Cell 160: 528-541.

O'Brien CP (2011). Drug addiction. In: Brunton LL, Chabner BA, Knollmann BC (eds). Goodman \& Gilman's the Pharmacological Basis of Therapeutics 12 edn. McGraw-Hill: New York.

Ogden CL, Carroll MD, Flegal KM (2014). Prevalence of obesity in the United States. JAMA 312: 189-190.

Organization WH (2000). Obesity: preventing and managing the global epidemic. Report of a WHO consultation. World Health Organ Tech Rep Ser 894: i-xii 1-253.

Ostlund SB, Balleine BW (2008). On habits and addiction: an associative analysis of compulsive drug seeking. Drug Discov Today Dis Models 5: 235-245.

Oswald KD, Murdaugh DL, King VL, Boggiano MM (2011). Motivation for palatable food despite consequences in an animal model of binge eating. Int J Eat Disord 44: 203-211.

Parylak SL, Cottone P, Sabino V, Rice KC, Zorrilla EP (2012). Effects of CB1 and CRF1 receptor antagonists on binge-like eating in rats with limited access to a sweet fat diet: lack of withdrawallike responses. Physiol Behav 107: 231-242.

Parylak SL, Koob GF, Zorrilla EP (2011). The dark side of food addiction. Physiol Behav 104: 149-156.

Pauli-Pott U, Albayrak O, Hebebrand J, Pott W (2010). Association between inhibitory control capacity and body weight in overweight and obese children and adolescents: dependence on age and inhibitory control component. Child Neuropsychol 16: 592-603.

Peciña S, Berridge KC (2005). Hedonic hot spot in nucleus accumbens shell: where do $\mu$-opioids cause increased hedonic impact of sweetness? J Neurosci 25: 11777-11786.

Pecoraro N, Reyes F, Gomez F, Bhargava A, Dallman MF (2004). Chronic stress promotes palatable feeding, which reduces signs of stress: feedforward and feedback effects of chronic stress. Endocrinology 145: 3754-3762.

Peterson CB, Miller KB, Crow SJ, Thuras P, Mitchell JE (2005). Subtypes of binge eating disorder based on psychiatric history. Int J Eat Disord 38: 273-276.

Petry NM, Barry D, Pietrzak RH, Wagner JA (2008). Overweight and obesity are associated with psychiatric disorders: results from the National Epidemiologic Survey on Alcohol and Related Conditions. Psychosom Med 70: 288-297.

Piazza PV, Deroche-Gamonet V (2013). A multistep general theory of transition to addiction. Psychopharmacology 229: 387-413.

Pursey KM, Stanwell P, Gearhardt AN, Collins CE, Burrows TL (2014). The prevalence of food addiction as assessed by the Yale Food Addiction Scale: a systematic review. Nutrients 6: 4552-4590.

Rada P, Avena NM, Hoebel BG (2005). Daily bingeing on sugar repeatedly releases dopamine in the accumbens shell. Neuroscience 134: 737-744.

Rada P, Bocarsly ME, Barson JR, Hoebel BG, Leibowitz SF (2010). Reduced accumbens dopamine in Sprague-Dawley rats prone to overeating a fat-rich diet. Physiol Behav 101: 394-400. 
Robbins TW, Curran HV, de Wit H (2012). Special issue on impulsivity and compulsivity. Psychopharmacology 219: 251-252.

Robinson MJ, Burghardt PR, Patterson CM, Nobile CW, Akil H, Watson SJ et al (2015). Individual differences in cue-induced motivation and striatal systems in rats susceptible to diet-induced obesity. Neuropsychopharmacology 40: 2113-2123.

Robinson TE, Berridge KC (1993). The neural basis of drug craving: an incentive-sensitization theory of addiction. Brain Res Brain Res Rev 18: 247-291.

Robson MJ, Noorbakhsh B, Seminerio MJ, Matsumoto RR (2012). Sigma-1 receptors: potential targets for the treatment of substance abuse. Curr Pharm Des 18: 902-919.

Rosen J, Tacy B, Howell D (1990). Life stress, psychological symptoms and weight reducing behavior in adolescent girls: a prospective analysis. Int J Eat Disorder 9: 17-26.

Rosen JC, Gross J, Vara L (1987). Psychological adjustment of adolescents attempting to lose or gain weight. J Consult Clin Psychol 55: 742-747.

Rosenbaum DL, White KS (2015). The relation of anxiety, depression, and stress to binge eating behavior. J Health Psychol 20: 887-898.

Rossetti C, Spena G, Halfon O, Boutrel B (2014). Evidence for a compulsive-like behavior in rats exposed to alternate access to highly preferred palatable food. Addict Biol 19: 975-985.

Sabino V, Cottone P, Blasio A, Iyer MR, Steardo L, Rice KC et al (2011). Activation of sigma-receptors induces binge-like drinking in Sardinian alcohol-preferring rats. Neuropsychopharmacology 36: 1207-1218.

Sabino V, Cottone P, Zhao Y, Iyer MR, Steardo L Jr., Steardo L et al (2009a). The sigma-receptor antagonist BD-1063 decreases ethanol intake and reinforcement in animal models of excessive drinking. Neuropsychopharmacology 34: 1482-1493.

Sabino V, Cottone P, Zhao Y, Steardo L, Koob GF, Zorrilla EP (2009b). Selective reduction of alcohol drinking in Sardinian alcohol-preferring rats by a sigma-1 receptor antagonist. Psychopharmacology 205: 327-335.

Sansone RA, Sansone LA (2013). Obesity and substance misuse: is there a relationship? Innov Clin Neurosci 10: 30-35.

Schmitz F, Naumann E, Trentowska M, Svaldi J (2014). Attentional bias for food cues in binge eating disorder. Appetite 80: 70-80.

Sedki F, Gardner Gregory J, Luminare A, D'Cunha TM, Shalev U (2015). Food restriction-induced augmentation of heroin seeking in female rats: manipulations of ovarian hormones. Psychopharmacology 232: 3773-3782.

Seeyave DM, Coleman S, Appugliese D, Corwyn RF, Bradley RH, Davidson NS et al (2009). Ability to delay gratification at age 4 years and risk of overweight at age 11 years. Arch Pediatr Adolesc Med 163: 303-308.

Selleck RA, Lake C, Estrada V, Riederer J, Andrzejewski M, Sadeghian K et al (2015). Endogenous opioid signaling in the medial prefrontal cortex is required for the expression of hungerinduced impulsive action. Neuropsychopharmacology 40: 2464-2474.

Shalev U (2012). Chronic food restriction augments the reinstatement of extinguished heroin-seeking behavior in rats. Addict Biol 17: 691-693.

Shalev U, Erb S, Shaham Y (2010). Role of CRF and other neuropeptides in stress-induced reinstatement of drug seeking. Brain Res 1314: 15-28.

Shank LM, Tanofsky-Kraff M, Nelson EE, Shomaker LB, Ranzenhofer LM, Hannallah LM et al (2015). Attentional bias to food cues in youth with loss of control eating. Appetite 87: 68-75.

Sharma S, Fernandes MF, Fulton S (2013). Adaptations in brain reward circuitry underlie palatable food cravings and anxiety induced by high-fat diet withdrawal. Int J Obes 37: 1183-1191.

Sidhpura N, Parsons LH (2011). Endocannabinoid-mediated synaptic plasticity and addiction-related behavior. Neuropharmacology 61: 1070-1087.

Silverstone J, Lascelles B (1966). Dieting and depression. $\mathrm{Br} J$ Psychiatry 112: 513-519.
Simon GE, Von Korff M, Saunders K, Miglioretti DL, Crane PK, van Belle $G$ et al (2006). Association between obesity and psychiatric disorders in the US adult population. Arch Gen Psychiatry 63: 824-830.

Smith DG, Robbins TW (2013). The neurobiological underpinnings of obesity and binge eating: a rationale for adopting the food addiction model. Biol Psychiatry 73: 804-810.

Smith KL, Rao RR, Velazquez-Sanchez C, Valenza M, Giuliano C, Everitt BJ et al (2015). The uncompetitive N-methyl-D-aspartate antagonist memantine reduces binge-like eating, food-seeking behavior, and compulsive eating: role of the nucleus accumbens shell. Neuropsychopharmacology 40: 1163-1171.

Stice E, Davis K, Miller NP, Marti CN (2008). Fasting increases risk for onset of binge eating and bulimic pathology: a 5-year prospective study. J Abnorm Psychol 117: 941-946.

Stirling LJ, Yeomans MR (2004). Effect of exposure to a forbidden food on eating in restrained and unrestrained women. Int J Eat Disord 35: 59-68.

Stoeckel LE, Weller RE, Cook EW 3rd, Twieg DB, Knowlton RC, Cox JE (2008). Widespread reward-system activation in obese women in response to pictures of high-calorie foods. Neuroimage 41: 636-647.

Stuber GD, Klanker M, de Ridder B, Bowers MS, Joosten RN, Feenstra MG et al (2008). Reward-predictive cues enhance excitatory synaptic strength onto midbrain dopamine neurons. Science 321: 1690-1692.

Stunkard AJ (1957). The dieting depression; incidence and clinical characteristics of untoward responses to weight reduction regimens. Am J Med 23: 77-86.

Svaldi J, Naumann E, Trentowska M, Schmitz F (2014). General and food-specific inhibitory deficits in binge eating disorder. Int $J$ Eat Disord 47: 534-542.

Tao R, Huang X, Wang J, Zhang H, Zhang Y, Li M (2010). Proposed diagnostic criteria for internet addiction. Addiction 105: 556-564.

Teegarden SL, Bale TL (2007). Decreases in dietary preference produce increased emotionality and risk for dietary relapse. Biol Psychiatry 61: 1021-1029.

Teegarden SL, Bale TL (2008). Effects of stress on dietary preference and intake are dependent on access and stress sensitivity. Physiol Behav 93: 713-723.

Tomasi D, Volkow ND (2013). Striatocortical pathway dysfunction in addiction and obesity: differences and similarities. Crit Rev Biochem Mol Biol 48: 1-19.

Tomiyama AJ, Dallman MF, Epel ES (2011). Comfort food is comforting to those most stressed: evidence of the chronic stress response network in high stress women. Psychoneuroendocrinology 36: 1513-1519.

Valenza M, Steardo L, Cottone P, Sabino V (2015). Diet-induced obesity and diet-resistant rats: differences in the rewarding and anorectic effects of D-amphetamine. Psychopharmacology 232: 3215-3226.

Vanderschuren LJ, Everitt BJ (2004). Drug seeking becomes compulsive after prolonged cocaine self-administration. Science 305: 1017-1019.

Velazquez-Sanchez C, Ferragud A, Moore CF, Everitt BJ, Sabino V, Cottone P (2014). High trait impulsivity predicts food addictionlike behavior in the rat. Neuropsychopharmacology 39: 2463-2472.

Velazquez-Sanchez C, Santos JW, Smith KL, Ferragud A, Sabino V, Cottone P (2015). Seeking behavior, place conditioning, and resistance to conditioned suppression of feeding in rats intermittently exposed to palatable food. Behav Neurosci 129: 219-224.

Volkow ND, Fowler JS (2000). Addiction, a disease of compulsion and drive: involvement of the orbitofrontal cortex. Cereb Cortex 10: $318-325$.

Volkow ND, Fowler JS, Wang GJ, Hitzemann R, Logan J, Schlyer DJ et al (1993). Decreased dopamine D2 receptor availability is associated with reduced frontal metabolism in cocaine abusers. Synapse 14: 169-177. 
Volkow ND, Wang GJ, Fowler JS, Telang F (2008a). Overlapping neuronal circuits in addiction and obesity: evidence of systems pathology. Philos Trans R Soc Lond B Biol Sci 363: 3191-3200.

Volkow ND, Wang GJ, Telang F, Fowler JS, Thanos PK, Logan J et al (2008b). Low dopamine striatal D2 receptors are associated with prefrontal metabolism in obese subjects: possible contributing factors. Neuroimage 42: 1537-1543.

Volkow ND, Wang GJ, Tomasi D, Baler RD (2013). The addictive dimensionality of obesity. Biol Psychiatry 73: 811-818.

Voon V, Derbyshire K, Ruck C, Irvine MA, Worbe Y, Enander J et al (2015). Disorders of compulsivity: a common bias towards learning habits. Mol Psychiatry 20: 345-352.

Wang GJ, Volkow ND, Logan J, Pappas NR, Wong CT, Zhu W et al (2001). Brain dopamine and obesity. Lancet 357: 354-357.

Warschburger P (2005). The unhappy obese child. Int J Obes 29 (Suppl 2): S127-S129.
Wells AS, Read NW, Laugharne JD, Ahluwalia NS (1998). Alterations in mood after changing to a low-fat diet. Br J Nutr 79: 23-30.

Wilfley DE, Friedman MA, Dounchis JZ, Stein RI, Welch RR, Ball SA (2000). Comorbid psychopathology in binge eating disorder: relation to eating disorder severity at baseline and following treatment. J Consult Clin Psychol 68: 641-649.

Wolf AM, Colditz GA (1998). Current estimates of the economic cost of obesity in the United States. Obe Res 6: 97-106.

Wray I, Dickerson MG (1981). Cessation of high frequency gambling and "withdrawal' symptoms. Br J Addict 76: 401-405.

Wu M, Hartmann M, Skunde M, Herzog W, Friederich HC (2013). Inhibitory control in bulimic-type eating disorders: a systematic review and meta-analysis. PLoS One 8: e83412.

Zapata A, Minney VL, Shippenberg TS (2010). Shift from goaldirected to habitual cocaine seeking after prolonged experience in rats. J Neurosci 30: 15457-15463. 